\title{
Relationship between Emotional Labor and Intrinsic Job Satisfaction: The Moderating Role of Gender
}

\section{Sarraf ARA*}

Sheikh Bahaei University, Isfahan, Iran

\begin{abstract}
Using a wide range of excitements by service staff indicates the important role of emotional labor in such jobs, which affect their job satisfaction. This study examines the relationship between emotional labor and intrinsic job satisfaction among salespersons. The study is a descriptive study of correlation type and field survey. A population consisted of 248 salespersons working in seven chain stores were selected through simple sampling. Data collection tools are standard questionnaires whose validity and reliability have been confirmed. Obtained data were analyzed using descriptive and inferential statistics tests and structural equation modeling and regression analysis. The findings of the research indicate that there is a significant difference between the level of emotional labor, surface acting and deep acting between women and men. There is also direct relationship between emotional labor and intrinsic job satisfaction. Additionally, the effect of gender moderator on the relationship between emotional labor and intrinsic job satisfaction was confirmed.
\end{abstract}

Keywords: Emotional labor; Deep acting; Surface acting; Intrinsic job satisfaction; Gender

\section{Introduction}

Emotions take up a large part of our lives. The direct and indirect presence of emotions can be seen in reasoning and rationality. Disregarding the emotions, their lack of management and neglect to express them, can cost a lot to humans.

Feelings are a part of organizational life, because organizations are made up of humans and humans also feel. The organization is the means by which people express, control, or deny their emotions, and on the other hand, they have the ability to modulate or intensify the emotions of individuals [1]. Management experts believe that organizations can achieve better performance by managing and organizing feelings. Thus, organizational emotion management is an important capability of organizations. This valuable resource can create a competitive advantage, and since it is a natural capability, imitation of it is difficult for competitors.

The emotional capacity of the organization, (1) Directs the employees in terms of promoting creativity, (2) coordinates the different feelings within the organization, (3) enables managers to be informed on time about the employees' emotional state and their degree of satisfaction [1].

Today, most companies in their highly competitive environment focus on managing the emotional behaviors of employees [2]. Employees, who repress their true emotions or pretend to obey the rules, suffer from a contradiction between the excitement and the exterior [3]. In this regard, managers should prepare their employees in the field of excitement and show positive emotions in dealing with clients and provide them with the necessary training in their interaction with customers, because research shows that a positive relationship between positive emotional representation of service employees with customer satisfaction [4].

Thus, considering the importance of employee satisfaction in improving sales growth, reducing the cost of attracting new customers, creating competitive advantages, and finally the sustainable growth and development of the service sector, the present study seeks to answer the question whether the work-related emotions have a significant impact on intrinsic job satisfaction or not.

\section{Emotional Labor}

Emotional labor, or work-related excitement, refers to situations in which employees, especially those who serve customer service, are required to express excitements that may be different from their actual thrills [5]. There are different definitions of emotional labor. Kim believes that it is the emotional management as part of the role of work [6]. Someone else shows that emotional labor is the use of various strategies to express emotions in interaction with the client [7].

Emotional labor is a kind of personalized emotional regulation, so that the person has some special excitement from his job that is expected to show [5].

Studies show that at least two-thirds of the interactions within an organization are associated with emotional labor [8] and emotional labor is greatly influences organizational desirable results at workplace [3]. Also, it affects individual and organizational results, physical and mental health and job satisfaction as well as customer service quality/ customer satisfaction and performance [9]. In order to provide better customer service, researchers paid a lot of attention to the importance of emotional labor and emotion management in the interaction between service staff and customers [10]. Service marketing research shows that positive emotional behavior such as smile during service delivery has a positive impact on customer satisfaction [11]. Because the apparent quality of the service is defined not only by the behavior of the service staff and the manner of operation and the way of speaking, but also by their emotional adjustment, most service organizations encourage their employees to manage emotions and feelings in service interactions in order to increase customer satisfaction [12].

*Corresponding author: Sarraf ARA, Assistant Professor of Management, Sheikh Bahaei University, Isfahan, Iran, Tel: +98 313681 6761; E-mail: a.r.akhavan@shbu.ac.ir

Recieved January 25, 2018; Accepted March 15, 2018; Published March 23, 2018

Citation: Sarraf ARA (2018) Relationship between Emotional Labor and Intrinsic Job Satisfaction: The Moderating Role of Gender. J Entrepren Organiz Manag 7: 227. doi: 10.4172/2169-026X.1000227

Copyright: (c) 2018 Sarraf ARA. This is an open-access article distributed under the terms of the Creative Commons Attribution License, which permits unrestricted use, distribution, and reproduction in any medium, provided the original author and source are credited. 
In the meantime, managers are forced to use a wide range of emotions, including positive and emotional excitement, compassion, sympathy, thoughts, companionship and agility, due to the diversity and scope of their field. They must also have the ability to recognize which feelings they should have in every situation. That is, managers must manage and control their different types of emotions. This reflects the important role of emotional labor and the regulation of emotions in management [13].

\section{Different levels of emotional labor}

Emotional labor has two different levels as follows:

Surface acting: When a person expresses his excitement only in appearance to satisfy expectations, through facial movements, change of his tone, his position, and his hints, without realizing his feelings [14]. Surface acting occurs when the emotional staff is present, which includes the suppressed emotional feelings and the imitation of emotions not sensed [15]. Employees may be intimidated or unshaken by clients to offer intimacy and suggestion. For example, a flight crew may approach nerve travelers with a sense of sympathy and understanding [16].

The involvement of a person in surface acting often causes a cognitive/emotional disagreement between representing the emotions required by the organization and the real experience of feeling that ultimately leads to burnout [17]. Based on the theory of cognitive dissonance, which states that service workers are tense or abnormal when displaying emotions that are not in line with their main emotions, surface acting has a negative relationship with job satisfaction.

Deep acting: The process of changing the excitement in order to experience and express emotions is appropriate [18]. Deep acting attempts to correct internal emotions and external expressions to harmonize them with rules [19]. In deep acting, employees create the expected or needed excitement within themselves [10].

Service workers who often engage in emotional labor, are often more satisfied with their job. Adelman [20] indicates employees who show real emotions in the work environment, have more intrinsic job satisfaction than those who often use surface acting. Although deep acting requires effort to change the emotional state of an individual, many research has found that such efforts not only don't lead to emotional exhaustion [21], but also lead to the spread of personal integrity, personal success and a sense of success [17]. Because deep acting does not include high levels of cognitive dissonance, it can lead to good status and increased job satisfaction.

\section{Emotion Regulation Strategies}

According to the theory of emotion regulation, individuals are involved in two different strategies for regulating their emotions.

\section{Antecedent-focused emotion regulating}

Processes data (input). Such strategies may be avoided, changed, or re-evaluated based on the potential emotional impact of some individuals or situations. Emotional labor is well aligned with this definition [22]. According to the theory of emotion regulation, emotional labor is the emotion control strategy in the job to successfully complete the interactions.

\section{Response-focused emotion regulating}

Processes output (output). These strategies address continuing emotional experiences, but they mostly emphasize physiological responses. Hence, emotional exhaustion is probably a good structure for this strategy [23].

\section{The Relationship between Emotional Labor and Job Satisfaction}

Job satisfaction is one of the most important concepts that have focused by many theoretical and fundamental efforts. This variable considered important at all levels of management and human resources of organizations. Job satisfaction is a set of evaluative feelings that employees have about their workplace [24]. Job Satisfaction is an important factor in the employee's perception of how well the job and the work environment are. Employees with high levels of job satisfaction are more likely to provide better services and thus lead to more satisfactory customer satisfaction assessments of the quality of services provided, which ultimately lead to better financial performance for the company.

Since a person with high job satisfaction has a positive emotion toward his job and a person with low job satisfaction has a negative emotion, it can be expected that job satisfaction affects many other organizational variables. Several researches have shown that job satisfaction is one of the important factors in increasing productivity, compassion of employees towards organization, attachment to the workplace and increasing the quantity and quality of work, establishing good and human relations in the workplace, creating the right communication, raise the spirit, love and interest in the work.

Therefore, if organizations choose frontline service employees based on their interpersonal skills and individuals seek jobs compatible with their personality, the "fit" between job demands and personal qualities may be high in these positions, thereby leading to increased job satisfaction.

In the context of the relationship between emotional labor and job satisfaction, there are several studies. A review of these studies shows that research on the relationship between these two structures has not achieved similar findings.

- Some of them have found positive relationships between emotional labor and job satisfaction [20]. Positive consequences of emotional labor are found in studies that examine service staff that interact with customers or have jobs that engage enormously with customers [25]. For example, in a research conducted in banking sector and hospitals, it was shown that emotional labor is positively associated with job satisfaction [26]. Wharton also proved that employees who find emotional labor jobs more satisfying was probably attracted to such jobs because they possess personal qualities especially suited to working with the public. Also, the results of qualitative studies show that there is a positive relationship when emotional labor involves emotion management of others [25], and the reason is that this experience is a kind of Self-development and empowerment [27].

- Some of them have found negative relationships between emotional labor and job satisfaction [28,29]. For example, a study shows that emotional work undermines job satisfaction [30].

- Another group of studies has found a more complex relationship between emotional labor and job satisfaction that does not necessarily confirm a meaningful relationship between these two structures. For example, Yang and Chang found that there was no meaningful relationship between surface action and job satisfaction, but there was a meaningful and direct relationship between deep action and job satisfaction [31]. Two different studies made by another 
researcher were led to contradiction. The results of first study show that those with more emotional labor do not have much job satisfaction, while the results of the second study indicated that emotional labor was not significantly associated with job satisfaction [20]. The contradictory findings of this study may be due to the nature of the jobs being studied. The first study is a job survey that requires a lot of emotional labor, while the second study examines a job that requires less emotional labor. Also these findings may be explained by the method of emotional labor undertaken, for instance, surface acting may lead to feelings of inauthenticity and consequently job dissatisfaction. Conversely, if an employee engages in deep acting this may lead to feelings of personal accomplishment and by extension, job satisfaction [32].

\section{Gender Effect on Emotional Labor}

Individual differences are important to consider in terms of the emotional experience, and gender matters in particular. Some scholars emphasize emotional labor in gender studies at work. For example, Grandey's presents a number of personal and organizational factors that relate to emotional labor. She suggests five individual difference and personality variables that should be examined in relation to emotion management; gender, emotional expressivity, emotional intelligence, self-monitoring, and affectivity [3]. Hochschild's [5] initial work on emotional labor focused on female flight attendants and she noted that women significantly outnumber men in the service industry. Her initial concern was that, due to their numerical superiority in service work, the negative aspects of emotional labor were disproportionately affecting women.

However, research has shown that women who perform emotional labor are significantly more satisfied than men who perform the same type of job [26]. This suggests that women may be socialized to handle the interpersonal demands of emotion management in service work, and this competency may lead them to have a more positive experience than their male counterparts. Perhaps this socialization may lead women to engage in deep acting to adhere to positive display rules, which should result in less emotional dissonance. In fact, Grandey [3] suggests that men may need more training in emotion management in a service setting. However, research has demonstrated a relationship between gender and emotional dissonance, such that women reported more cases in which they felt differently than they expressed [32]. It is possible that while more satisfied, women may have higher levels of stress or psychological ailments that are related to their successful suppression of feelings. The contradictory research on the effects of emotional labor on women may be explained by whether they engage in deep acting or surface acting. Deep acting may enable women to experience positive emotions, which may in turn result in increased affective well-being. However, surface acting while producing the appropriate expressive behavior, will lead to emotional dissonance which can lead to stress.

Researchers have found that the skills women give to organizations are often overlooked, and although they have a significant role in the organization, their efforts are not well compensated. Emotional labor is an individual effort to present emotions in the manner desired by the organization. It can be assumed that employers expect more emotional labor from their employees, have more effective engagement with customers, better internal relationships, and superior performance of the program. The results of some studies indicate that organizations that employ more women have been able to raise the overall performance of the organization.

\section{Research Method}

The current study considers emotion regulation process and intrinsic job satisfaction as one of the consequences of emotional labor. This review also emphasizes the role of gender as one of various individual factors affect the emotional labor process. Other factors like emotional intelligence, self-monitoring, affectivity etc. are also effective, which are not addressed in this study. A sample of 248 salespersons from 7 different chain stores participated in this study. Participants were required to engage in a significant amount of customer interaction as a part of their job. The sample was $54 \%$ female and had an overall mean age of 35 , with a range from 21 to 56 . Average work experience for this sample was approximately five years and ranged from six months to about 12 years.

\section{Measures}

To assess surface acting and deep acting, two three-item measures from [17], originally developed by Brotheridge and Lee were used [33]. The focus of these items was the particular service interaction an employee had just completed with a customer, not the employee's preferred emotional labor strategy in general [10]. The response scale ranging from 1, "strongly disagree," to 7, "strongly agrees."

To assess job satisfaction, The Minnesota Satisfaction Questionnaire (MSQ) was used. This is a self-reporting measure, suitable for individuals of all school levels that can be administrated separately or individually.

The MSQ short form includes only 20 of the 100 original items, namely, the ones that better represented each of the original subscales [34].

The 20 MSQ-short version items are rated on a 5-point Likert scale ( 1 "very dissatisfied with this aspect of my job", 2 "dissatisfied with this aspect of my job", 3 "can't decide if I'm satisfied or dissatisfied with this aspect of my job", 4 "satisfied with this aspect of my job" and 5 "very satisfied with this aspect of my job"). Item responses are summed or averaged to create a total score - the lower the score, the lower the level of job satisfaction.

According to many studies, there are two subscales for this questionnaire: intrinsic job satisfaction and extrinsic job satisfaction. In this research, only intrinsic job satisfaction which is more associated with emotional labor is considered. Questions related to intrinsic job satisfaction have been extracted from Martins [35].

The internal consistency reliability of scales was measured by the Cronbach's alpha coefficient. Table 1 shows alpha values for each of the study variables. All scales demonstrated good reliability, where an alpha value of 0.70 is the minimum considered acceptable [36].

\section{Research Questions}

An important aspect that must be considered is that emotional labor is gendered, in the sense that there clearly exists a sexual division of emotional labor [37]. Men are generally confided to tasks that demand aggressiveness and curtness. Men frequently find themselves in jobs where they must be aggressive towards those that transgress rules, while women are more likely to accomplish tasks while restraining aggression and anger toward others. Women generally are given tasks that demand nurturing, tenderness, sensitivity, and intuition. They are supposedly afraid of things that men are not supposed to fear and are often described as compassionate, charitable, agreeable, and kind. Furthermore, this sexual division of emotional labor exists between jobs and between workers in the same occupation. 
Citation: Sarraf ARA (2018) Relationship between Emotional Labor and Intrinsic Job Satisfaction: The Moderating Role of Gender. J Entrepren Organiz Manag 7: 227. doi: 10.4172/2169-026X.1000227

Page 4 of 6

\begin{tabular}{|c|c|c|c|}
\hline Variable name & S. No & Questions & Alpha \\
\hline \multicolumn{4}{|l|}{ Surface acting } \\
\hline & 1 & I tried to actually experience the emotions I had to show to the customer. & \multirow[t]{3}{*}{$0 / 920$} \\
\hline & 2 & I worked hard to feel the emotions that I needed to show to the customer. & \\
\hline & 3 & I made a strong effort to actually feel the emotions that I needed to display toward the customer. & \\
\hline \multicolumn{4}{|l|}{ Deep acting } \\
\hline & 4 & I just pretended to have the emotions I needed to display to the customer. & \multirow[t]{3}{*}{$0 / 863$} \\
\hline & 5 & I put on a 'mask' in order to display the emotions my manager wants me to display. & \\
\hline & 6 & I put on a 'show' or 'performance' when interacting with the customer. & \\
\hline \multicolumn{4}{|l|}{ Intrinsic job satisfaction } \\
\hline & 7 & The chance to work alone on the job. & \multirow[t]{6}{*}{$0 / 898$} \\
\hline & 8 & The chance to be somebody in the community. & \\
\hline & 9 & The chance to do things for other people. & \\
\hline & 10 & The chance to tell people what to do. & \\
\hline & 11 & The chance to do something that makes use of my abilities. & \\
\hline & 12 & The chance to try my own methods of doing the job. & \\
\hline
\end{tabular}

Table 1: Questions and Cronbach's alpha values for research variables.

\begin{tabular}{|c|c|c|c|c|c|c|c|c|}
\hline \multirow[t]{2}{*}{ Variable } & \multirow[t]{2}{*}{ Gender } & \multirow[t]{2}{*}{$\mathbf{N}$} & \multirow[t]{2}{*}{ Mean } & \multicolumn{2}{|c|}{ Variance Equation Test } & \multicolumn{2}{|c|}{ Independent t-test } & \multirow[t]{2}{*}{ Mean diff. } \\
\hline & & & & $\begin{array}{l}\text { Levine's } \\
\text { Statistics }\end{array}$ & Sig. & $\mathbf{t}$ & Sig. & \\
\hline \multirow[t]{2}{*}{ Emotional labor } & Female & 114 & $61 / 21$ & \multirow[t]{2}{*}{$107 / 1$} & \multirow[t]{2}{*}{$080 / 0$} & \multirow[t]{2}{*}{$-0 / 013$} & \multirow[t]{2}{*}{$009 / 0$} & \multirow[t]{2}{*}{$69 / 1$} \\
\hline & Male & 134 & $92 / 19$ & & & & & \\
\hline \multirow[t]{2}{*}{ Surface acting } & Female & 114 & $51 / 7$ & \multirow[t]{2}{*}{$013 / 0$} & \multirow[t]{2}{*}{$909 / 0$} & \multirow[t]{2}{*}{$002 / 0-$} & \multirow[t]{2}{*}{$003 / 0$} & \multirow[t]{2}{*}{$17 / 2$} \\
\hline & Male & 134 & $68 / 9$ & & & & & \\
\hline \multirow[t]{2}{*}{ Deep acting } & Female & 114 & $10 / 14$ & \multirow[t]{2}{*}{$180 / 0$} & \multirow[t]{2}{*}{$672 / 0$} & \multirow[t]{2}{*}{ 009/0- } & \multirow[t]{2}{*}{$002 / 0$} & \multirow[t]{2}{*}{$86 / 3$} \\
\hline & Male & 134 & $24 / 10$ & & & & & \\
\hline
\end{tabular}

Table 2: Comparison of respondents' views based on gender.

People differ in terms of how they construe themselves. Women are more likely than men to construe themselves in interdependent terms, meaning in terms of their relationships with others [38]. Given women's intensified interdependent self-construal, we maintain that emotional behaviors are more important for women compared to men, and thus lead to a more emotional labor for women than men.

Question 1: Is there any significant difference between female and male employees in emotional labor?

Question 2: Is there any significant difference between female and male employees in surface acting?

Question 3: Is there any significant difference between female and male employees in deep acting?

Since gender is a two-level variable, it is necessary to use an independent $t$-test to examine the significance of the difference between the two groups of women and men and the probable difference between their views.

For this purpose, it must first be determined whether the variance of the two groups is the same. Given the Levine's statistics and the significant values in Table 2, these values are greater than $5 \%$ for all research variables. Based on this, the equality of variance of all variables in relation to gender is confirmed.

Also, the results in Table 2 show that for all variables, the significance of the $t$ test is less than the error rate of $5 \%$, and therefore the difference in the views of women and men on these variables is significant. The average observed difference between two groups also suggests this, as it shows a large difference.

Also, according to the mean values of variables presented in Table 2 by gender, it is shown that the emotional labor and deep acting are higher for women and the value of the surface acting is higher for men.

\section{Research Hypotheses}

Regarding the described relationship between emotional labor and job satisfaction, the focus of this study is to examine the relationship between these two structures. Given the described emotional regulation strategies and considering that emotional labor is an emotion regulation strategy, the focus of the study is on the antecedent-focused emotion regulation strategy, and this study examines the effect from this view. Considering the different levels of emotional labor described, the study examines the effect of different levels of emotional labor on intrinsic job satisfaction $[39,40]$.

Hypothesis 1: Emotional labor is positively correlated with intrinsic job satisfaction.

Hypothesis 2: Surface acting is negatively correlated with intrinsic job satisfaction.

Hypothesis 3: Deep acting is positively correlated with intrinsic job satisfaction.

The results of testing the first, second and third hypotheses of this study, which were carried out using the structural equation model using Smart PLS software, are presented in Table 3. Based on the numbers in this table, the Following results can be obtained.

The significant coefficient for the relationship between emotional labor and intrinsic job satisfaction is 2.245, so emotional labor affects intrinsic job satisfaction, and since the impact factor is equal to 0.447 , this relationship is positive and has a moderate intensity. Thus, the first hypothesis of the research is confirmed.

The significant coefficient for the relationship between surface 


\begin{tabular}{|l|c|c|c|}
\hline Relation & Impact Factor & t-Statistic \\
\hline Emotional labor $\rightarrow$ Job satisfaction & $447 / 0$ & $2 / 245$ & Result \\
\hline Surface acting $\rightarrow$ Job satisfaction & $371 / 0-$ & $3 / 564$ & Confirmed \\
\hline Deep acting $\rightarrow$ Intrinsic job satisfaction & $803 / 0$ & $7 / 668$ \\
\hline
\end{tabular}

Table 3: Test results of hypotheses $1,2 \& 3$ of the study.

\begin{tabular}{|c|c|c|c|c|c|c|c|c|}
\hline & $\mathbf{R}$ & R2 & $\mathbf{F}$ & $\mathbf{P}$ & B & Beta & $\mathbf{t}$ & $\mathbf{P}$ \\
\hline Emotional labor & $0 / 61$ & $0 / 38$ & $61 / 81$ & 0/001 & $0 / 43$ & $0 / 61$ & $5 / 32$ & $0 / 001$ \\
\hline \multirow[t]{2}{*}{ Gender } & \multirow[t]{2}{*}{$0 / 65$} & \multirow[t]{2}{*}{$0 / 43$} & \multirow[t]{2}{*}{$39 / 12$} & \multirow[t]{2}{*}{$0 / 001$} & $0 / 2$ & $0 / 32$ & $3 / 37$ & $0 / 001$ \\
\hline & & & & & $0 / 27$ & $0 / 39$ & $3 / 16$ & 0/001 \\
\hline \multirow[t]{3}{*}{ Emotional labor $\times$ Gender } & \multirow[t]{3}{*}{$0 / 57$} & \multirow[t]{3}{*}{$0 / 45$} & \multirow[t]{3}{*}{$37 / 45$} & \multirow[t]{3}{*}{$0 / 001$} & $0 / 060$ & $0 / 58$ & $4 / 73$ & $0 / 001$ \\
\hline & & & & & $0 / 61$ & $0 / 89$ & $0 / 32$ & $0 / 34$ \\
\hline & & & & & 0/015 & $0 / 38$ & $3 / 46$ & 0/017 \\
\hline
\end{tabular}

Table 4: Test results of hypotheses 4 of the study.

acting and intrinsic job satisfaction is 3.646 , so surface acting affects intrinsic job satisfaction, and since the impact factor is equal to-0.371, this relationship is negative and has a low intensity.

Thus, the second hypothesis of the research is confirmed.

The significant coefficient for the relationship between deep acting and intrinsic job satisfaction is 7.668 , so deep acting affects intrinsic job satisfaction, and since the impact factor is equal to 0.803 , this relationship is positive and of great intensity.

Thus, the third hypothesis of the research is confirmed.

Also, this study examines the moderating effect of gender on relationship between emotional labor and intrinsic job satisfaction.

Hypothesis 4: Gender has a moderating effect on relationship between emotional labor and intrinsic job satisfaction.

The moderator regression analysis was used to examine the role of gender moderator in the relationship between emotional labor and intrinsic job satisfaction. As seen in Table 4, the interaction between gender and emotional labor increases the amount of explained variance of intrinsic job satisfaction from 0.38 to 0.45 . Regression coefficients related to gender interaction and emotional labor indicates that this increase is statistically significant.

\section{Conclusion}

It can be said that the occurrence of real feelings and deep acting is one of the motivational factors of job satisfaction, which, if any, will result in job satisfaction, so that the person expressing his actual feelings and deep acting, his job satisfaction will be higher. Surface acting, however, are among the health factors of job satisfaction; their existence at a certain level is not result in job satisfaction and only prevents dissatisfaction. For example, if surface acting is above average, causing job dissatisfaction, as the individual constantly has to show unrealistic feelings. In this study, the level of surface action is lower than the average, which, however, can be said it does not provide job dissatisfaction, but these conditions also have no effect on the job satisfaction of individuals. But according to results of study, job satisfaction is provided when the amount of emotional labor is high in terms of real feelings and deep acting. Indeed, if people express their true feelings and take deep acting, they will have more job satisfaction, and if real feelings of individuals are consistent with the behaviors they are expected to have in the workplace, they will not only feel job satisfaction, but also they work with better quality. Therefore, it is suggested that appropriate feelings and beliefs that interested by the organization and lack or disagree with personnel, transfer to them by appropriate training courses. During these theoretical and practical training, the person will be exposed to deep acting along with encouragement and motivation, and over time, deep acting will become the true feelings of the individual.

\section{References}

1. Akgu A, Keskin H, Byrne J (2009) Organizational emotional capability, product and process. J Eng Technol Manage 26: 103-130.

2. Diefendorff JM, Richard EM (2003) Antecedents and consequences of emotional display rule perceptions. J Appl Psychol 88: 284-294.

3. Grandey AA (2000) Emotion regulation in the workplace: a new way to conceptualize emotional labor. J Occup Health Psychol 5: 95-110.

4. Soderlund M, Rosengren S (2011) The happy versus unhappy service worker in the service encounter: assessing the impact on customer satisfaction. JRCS 17: $161-169$.

5. Hochschild AR (1979) Emotion work, feeling rules, and social structure. Am J Sociol 85: 551-575.

6. Kim HJ (2008) Hotel service providers, emotional labor: The antecedents and effects on burnout. Int J Hosp Manag 27:151-161.

7. Goodwin RE, Groth M, Frenkel SJ (2011) Relationships Between Emotional Labor, Job Performance, and Turnover. J Vocat Behav 79: 538-548.

8. Chau SL (2007) Examining the Emotional Labor Process: a Moderated Model of Emotional Labor and its Effects on Job Performance.

9. Tsai WC, Huang YM (2002) Mechanisms linking employee affective delivery and customer behavioral intentions. J Appl Psychol 87: 1001-1008.

10. Groth M, Henning-Thurau T, Walsh G (2009) Customer reactions to emotional labor: the roles of employee acting strategies and customer detection accuracy. Acad Manag J 52: 958-974.

11. Soderlund M, Rosengren S (2008) Revisiting the smiling service worker and customer satisfaction. Int J Serv Ind Manag 19: 552-574.

12. Bryman A (2004) The Disneyization of Society. Sociol Rev 47: 25-47.

13. Humphrey RH, Pollack JM, Hawver T (2008) Leading with emotional labor. J Manag Psychol 23: 151-168.

14. Lazanyi KR (2009) Factors affecting emotional labor, Emotional labor in oncology. Budapest: Institute of Management Department of Organizational Behavior.

15. Lovatt M, Nanton V, Roberts J, Ingleton C, Noble B, et al. (2015) The provision of emotional labor by health care assistants caring for dying cancer patients in the community: A qualitative study into the experiences of health care assistants and bereaved family careers. Int J Nurs Stud 52: 271-279.

16. Fu YK (2013) The influence of internal marketing by airlines on customer oriented behavior: A test of the mediating effect of emotional labor. J Air Transp Manag 32: 49-57.

17. Grandey A (2003) when 'the show must go on': surface and deep acting as determinants of emotional exhaustion and peer-rated service delivery. Acad Manag J 46: 86-96. 
Citation: Sarraf ARA (2018) Relationship between Emotional Labor and Intrinsic Job Satisfaction: The Moderating Role of Gender. J Entrepren Organiz Manag 7: 227. doi: 10.4172/2169-026X.1000227

Page 6 of 6

18. Wang G (2011) What role does leaders emotional labor play in effective leadership? lowa: lowa University.

19. Chu KH, Baker MA, Murmann SK (2012) When we are onstage, we smile: The effects of emotional labor on employee work outcomes. Int J Hosp Manag 31: 906-915

20. Adelmann PK (1989) Emotional labor and employee well-being. University of Michigan, Ann Arbor, MI, Unpublished Dissertation.

21. Judge TA, Fluegge WE, Hurst $C$ (2009) Is emotional labor more difficult for some than for others? A multilevel, experience sampling study. J Pers Psychol 62: $57-88$.

22. Gross JJ (1998) Antecedent- and response-focused emotion regulation: Divergent consequences for experience, expression, and physiology. J Pers Soc Psychol 74: 224-237.

23. Kiffin-Peterson SA, Jordan CL, Soutar GN (2011) The big five, emotional exhaustion and citizenship behaviors in service settings: The mediating role of emotional labor. Personal Individ Differ 50: 43-48.

24. Skinner SJ, Dubinsky AJ, Donnelly JH (1984) The use of social bases of power in retail sales. JPSSM 4: 48-56.

25. Pugliesi K (1999) The consequences of emotional labor: Effects on work stress, job satisfaction, and well-being. Motiv Emot 23: 125-154.

26. Wharton AS (1993) The affective consequences of service work. Work and Occupations 20: 205-232.

27. Leidner R (1993) Fast food, fast talk: Service work and the routinization of everyday life. Berkeley, CA: University of California Press.

28. Abraham R (1998) Emotional dissonance in organizations: Antecedents, consequences, and moderators. Genet Soc Gen Psychol Monogr 124: 229-246.

29. Morris JA, Feldman DC (1997) Managing Emotions in the Workplace. JPSSM 9: $257-274$.
30. Zapf D, Holz M (2006) On the positive and negative effects of emotion work in organizations. Eur J Work Organ Psy 15: 1-28.

31. Yang FH, Chang CC (2008) Emotional labor, job satisfaction and organizationa commitment amongst clinical nurses: A questionnaire survey. Int J Nurs Stud 45: $879-887$.

32. Kruml SM, Geddes D (1998) Exploring the dimensions of emotional labor: the heart of Hochschild`s work. Manag Commun Q 14: 8-49.

33. Brotheridge CM, Lee RT (2003) Development and validation of the emotional labour scale. J Occup Organ Psychol 76: 365-379.

34. Ahmadi K, Kolivand A (2007) Stress and Job Satisfaction among Air Force Military Pilots. JSS 3: 159-163.

35. Martins H (2008) Impact of Firm-Promoted Accreditation of Prior Learning Processes on the Worker-Organization Relationship: A Cross-Sectional Survey in Portuguese Industrial Firms.

36. Nunnally JC, Bernstein IH (1994) Psychometric theory. New York, NY McGraw-Hill.

37. Heller A (1980) The emotional division of labor between the sexes. Socia Praxis 7: 205-218

38. Cross SE, Bacon PL, Morris ML (2000) The relational-interdependent selfconstrual and relationships. J Pers Soc Psychol 78: 791-808.

39. Hochschild AR (1983) The Managed Heart: Commercialization of Human feeling. Oakland: University of California Press.

40. Homburg C, Stock RM (2004) The Link between Sales people's Job Satisfaction and Customer Satisfaction in a Business-To-Business Context: a dyadic analysis. J Acad Mark Sci 32: 144-158. 